\title{
Effect of Nitric Acid on the Low Fluorescing Performance of Drilling Fluid Lubricant Based Animal and Vegetable Oils
}

\author{
Feng-shan Zhou, ${ }^{1}$ Zheng-qiang Xiong, ${ }^{1,2}$ Bao-lin Cui, ${ }^{1}$ Feng-bao Liu, ${ }^{1,3}$ \\ Guang-huan $\mathrm{Li}^{4}{ }^{4}$ Jin-ran Wei, ${ }^{4}$ and $\mathrm{Hua} \mathrm{Cui}^{4}$ \\ ${ }^{1}$ School of Materials Science and Technology, China University of Geosciences, Beijing 100083, China \\ ${ }^{2}$ Beijing Institute of Exploration Engineering, Beijing 100083, China \\ ${ }^{3}$ Tabei Exploratory \& Development Department, PetroChina Tarim Oilfield Company, Korla 841000, China \\ ${ }^{4}$ Drilling Fluid Technology Service Company, CNPC Bohai Drilling Engineering Ltd., Tianjin 300280, China
}

Correspondence should be addressed to Feng-shan Zhou; zhoufs@cugb.edu.cn

Received 5 September 2013; Accepted 21 October 2013

Academic Editor: Yizhuang Xu

Copyright (c) 2013 Feng-shan Zhou et al. This is an open access article distributed under the Creative Commons Attribution License, which permits unrestricted use, distribution, and reproduction in any medium, provided the original work is properly cited.

\begin{abstract}
After synthesis of mixed fatty acid triethanolamine ester surfactant based on animal and vegetable mixed oils, the reaction solution was added into $4 \%$ (wt/wt) liquid nitric acid or $9 \%$ (wt/wt) solid nitric acid as eliminating fluorescent agent continuing to react from 1 to 2 hours. The low fluorescence lubricant named E167 for drilling fluid was prepared, in which maximum fluorescence intensity $\left(F_{\max }\right)$ was less than 10 in three-dimensional fluorescence spectra of excitation wavelength range. When the E167 was added into fresh water based drilling fluid at the dosage of $0.5 \%$ (wt/wt), the sticking coefficient reduced rate $\left(\Delta K_{f}\right)$ is $78 \%$ and the extreme pressure (E-P) friction coefficient reduced rate $(\Delta f)$ is $79 \%$. In the case of $4 \%$ brine mud with $0.5 \%$ (wt/wt) E167 in it, the $\Delta K_{f}$ and $\Delta f$ are $75 \%$ and $62 \%$, respectively. After the hot rolling ageing test $180^{\circ} \mathrm{C} \times 16 \mathrm{~h}$ with the $\mathrm{E} 167$ was added into fresh water based drilling fluid at the dosage of $1 \%$ (wt/wt), the $\Delta K_{f}$ and $\Delta f$ are greater than $70 \%$, which shows a much better lubrication properties of strong resistance to high temperature. The fresh water based drilling fluid which contains $1 \%$ (wt/wt) E167 is almost nonfoaming even after hot rolling ageing $120^{\circ} \mathrm{C} \times 16 \mathrm{~h}$.
\end{abstract}

\section{Introduction}

In the process of oil and gas drilling, in order to reduce the friction between drilling string and borehole, drilling string and casing, together with reducing the drill string torque and tripping resistance, lubricant often need to be added, thus avoiding sticking accident and improving the drilling speed.

The most commonly used liquid lubricants for drilling fluid are mineral oils and vegetable oils. The mineral oils are difficult to biodegrade, which causes serious pollution problems to the environment, and the high grade of fluorescence is unfavorable for geological logging. In the case of vegetable oils, with properties of low toxicity, good biodegradability, resource renewability, and low fluorescence level, it is a kind of lubricant for environment friendly using as drilling fluid with promising application [1-7].

There are at least three problems in unmodified vegetable oils [8-12]: (1) the vegetable oils have low thermal stability in the process of hydrolysis, which are easy to saponify in alkaline environment, producing bubble of anion surfactant; (2) the adsorption consumption of water-soluble anion surfactant in the debris and borehole formation is larger than that of oil-soluble fat, which means that the consumption of lubricant after saponification is faster; namely, the lubricant after saponification is not durable; (3) with poor oxidation stability, the oil is easy to deteriorate resulting in stinking of drilling fluid, reducing and even losing the lubricating property. Therefore, chemical modification of vegetable oil is needed. The methods involved include hydrogenation [13], esterification [14, 15], and epoxidation [16].

The esterification modification of oil is studied in this paper using mixed oil as raw material, and the unsaturated bond of oil molecule was broken in the presence of nitric acid, and then a kind of low fluorescence lubricant with excellent lubricity was obtained. 


\section{Preparation and Performance Evaluation of Low Fluorescence Lubricant}

2.1. Materials and Apparatus. The animal oil and vegetable oil were purchased, and solid nitric acid was prepared in our group. The purity of acid catalyst, triethanolamine, and nitric acid is all CP and GC for n-hexane.

The apparatus for measuring the adhesion coefficient was received Qingdao Haitongda Special Instruments Company; extreme pressure (E-P) lubrication device, OFI, USA; F-4600 fluorescence spectrophotometer, Hitachi, Japan; ZNN-D6Ssix speed rotational viscometer and ZNS-2A-Low Pressure Filter Press, Qing Dao Haitongda Special Instruments Company; Infrared Spectrometer, Spectrum 100, Perkin Elmer, USA.

\subsection{Preparation of Low Fluorescence Lubricant E167. Certain} amounts of animal oil, vegetable oil, and acid catalyst were added into a three-necked flask equipped with a magnetic stirring bar, thermometer, and reflux condenser. The mixture was heated to corresponding temperature under stirring in given time, obtaining the ordinary lubricants without eliminating fluorescence. Then, the right amount of agent for eliminating fluorescence was added and the reaction continues for a certain time. Then, the target product was obtained.

2.3. Evaluation of Fluorescence Properties. At present, the UV visual for grading analysis method is commonly used for evaluating the fluorescent of drilling fluid lubricant. However, the method has the following problems [17]. (1) The wavelength emitted from UV lamp is around $365 \mathrm{~nm}$, which is not enough to excite the fluorescence with wavelength lower than $365 \mathrm{~nm}$. (2) Technically, it is difficult to accurately distinguish the fluorescence below 7 grades, using fluorescence logging instrument for naked-eye observation. (3) This method is only qualitative, but not quantitative, and with poor reproducibility. Therefore, according to the method described in patent by Patel [18], the fluorescence intensity of the lubricant $F_{\max }$ was quantitatively measured by the three-dimensional fluorescence spectroscopy, and the three-dimensional fluorescence spectra were obtained according to the optimal excitation wavelength and emission wavelength of EM. Methods and parameters are as follows: mix the test sample with $\mathrm{n}$-hexane according to the mass ratio $1: 400$ and then measure the fluorescence properties with fluorescence spectrophotometer; both excitation and emission slit widths were fixed at $2.5 \mathrm{~nm}$, and scan rate was selected at $1200 \mathrm{~nm} \mathrm{~min}^{-1}$ and PMT voltage at $700 \mathrm{~V}$.

2.4. Evaluation of Lubricity. The adhesion coefficient reduced rate $\left(\Delta K_{f}\right)$ and lubrication coefficient reduced rate $(\Delta f)$ are evaluation indicators of lubricity. The evaluation methods are according to drilling fluid liquid lubricant technical indicators Q/SY 1088-2007 [19].

2.5. The Evaluation of Rheological Properties. The rheological parameters apparent viscosity $(\mathrm{AV})$, plastic viscosity $(\mathrm{PV})$,

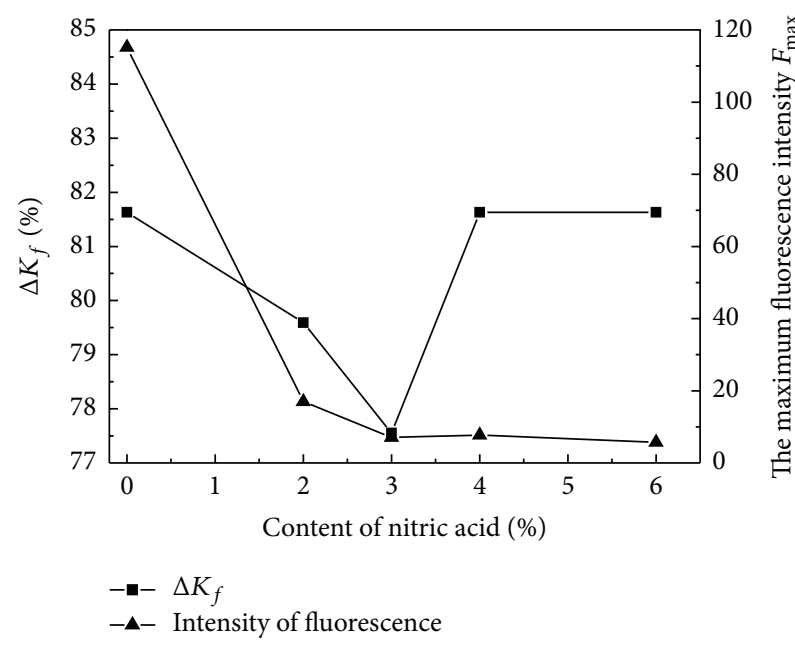

Figure 1

yield point (YP), and filtration at the room temperature $\left(\mathrm{FL}_{\mathrm{API}}\right)$ were investigated according to the first part of the field testing of drilling GB-T 16783.1-2006 [20].

2.6. Evaluation of Foamability. The method of foamability evaluation was performed referring to the technical requirements and analytical methods of drilling fluid lubricant Q/SY TZ 0022-2000 [21].

\section{Results and Discussion}

3.1. The Mechanism of Eliminating Fluorescence. Concentrated nitric acid in the reaction system decomposed nitrogen dioxide, with which the nitration reaction of unsaturated bond on the vegetable oil molecular chain occurred at high temperature [22]. The mechanism of reaction was proposed (see Figure 1).

According to the theory of fluorescence spectroscopy, the main functional groups of fluorescence are double bond, conjugated double bonds, benzene, and fused ring structure with $\pi$ electron, wherein the benzene and fused ring structure have strong fluorescence emission property [23]. Therefore, after the oxidation of double bonds on the molecular chain of vegetable oil, the amount of $\pi$ bond decreases and the fluorescence intensity of lubricant is weakened.

With cheap and strong oxidation characteristics, the nitric acid was chosen as the fluorescent eliminating agent, which broke the $\pi$ bond of double bonds and reduced the fluorescence level, and then the low fluorescence lubricant was obtained.

\subsection{The Optimization of Eliminating the Fluorescence}

3.2.1. Effect of Nitric Acid Content on Properties of Low Fluorescence Lubricant. At a certain temperature, fixing the amount of lubricants, the liquid nitric acid was changed to react for $1 \mathrm{~h}$, and the effect of nitric acid content on properties of low fluorescence lubricant was shown in Figure 2. 


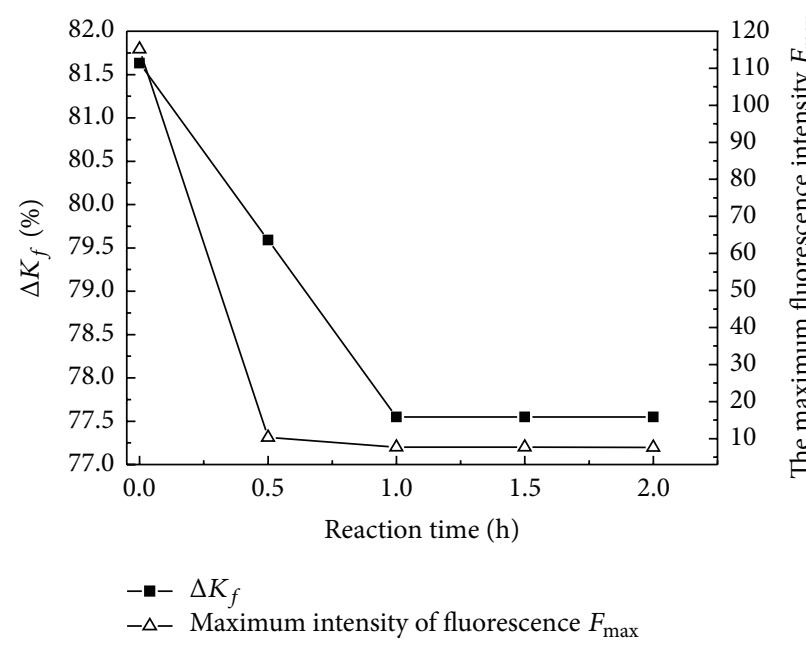

Figure 2: Effect of nitric acid content on properties of low fluorescence lubricant.

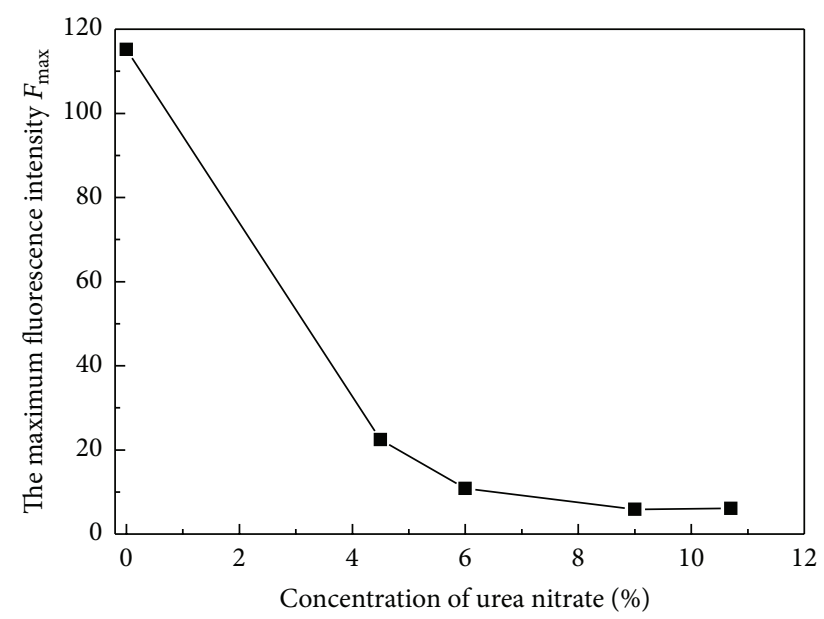

FIGURE 3: Effect of reaction time on performance of low fluorescence lubricant.

It can be seen from Figure 2 that the maximum fluorescence intensity of low fluorescence lubricant decreases gradually with the increase of nitric acid content, while the $\Delta K_{f}$ decreases first and then increases. When the dosage of nitric acid is $4 \%$ (wt/wt), the fluorescence properties showed the lowest maximum fluorescence intensity $\left(F_{\max } 7.725\right)$ and high value of $\Delta K_{f}(81.63 \%)$. So $4 \%$ of nitric acid content is chosen.

3.2.2. Effect of Reaction Time on Performance of Low Fluorescence Lubricant. At high temperature, the effect of reaction time on properties of low fluorescence lubricant was investigated after adding $4 \%$ of liquid nitric acid.

It can be seen in Figure 3 that the performance of low fluorescence lubricant presents regular changes with time changing. The value of $\Delta K_{f}$ reduced to remain changeless after $77.55 \%$, while the maximum fluorescence intensity decreased in larger in half an hour and then changed little after one hour.

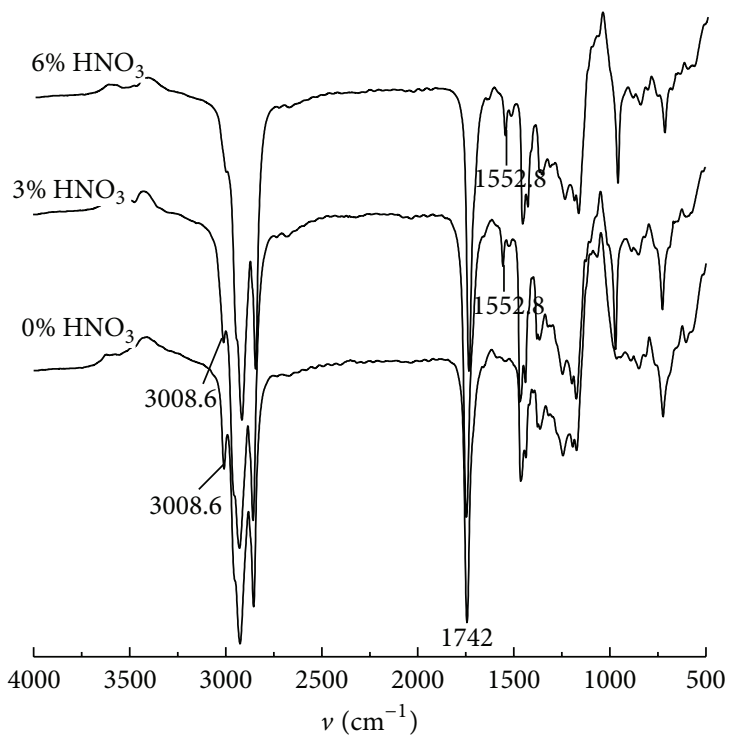

FIGURE 4: Effect of urea nitrate content on the maximum fluorescence intensity of low fluorescing lubricant.

As the reaction time increased, the unsaturated bonds were oxidated, then a part of the molecular chain was broken into small molecular compounds, leading to a reduction of the lubrication performance, and the fluorescence of lubricant intensity decreased meanwhile. In consideration of the fact that the value of $\Delta K_{f}$ is $77.55 \%$ after 1 hour, the reaction time for eliminating fluorescence was 1 hour.

3.2.3. Influence of Urea Nitrate Amount on the Maximum Fluorescence Intensity of Low Fluorescing Lubricant. There is danger of using nitric acid liquid operating at high temperature; hence, it is necessary to use urea nitrate for instead. At the same conditions, the effect of urea nitrate content on performance of low fluorescence lubricant was also investigated at fixed reaction time (1 hour).

As shown in Figure 4, the value of the maximum fluorescence intensity reduced with the urea nitrate content increasing. The intensity value decreased to 5.871 when the amount of urea nitrate was increased to $9 \%$. The low fluorescence lubricant produced by urea nitrate is with high freezing point and obvious particle, and it is easy to adhere to beaker. However, that produced by liquid nitrate does not have these disadvantages. Even so, the liquid urea nitrate is easy to store and use, and is of low cost as well. Whether using urea nitrate or liquid nitric acid as the fluorescent eliminating agent depends on the manufacturer.

3.2.4. The Effect of Eliminating Fluorescence Reaction on the Structure of Lubricant. The low fluorescence lubricants prepared with different dosages of nitric acid (reaction time $1 \mathrm{~h}$ ) were characterized by FTIR, and the results were demonstrated in Figure 5.

It can be seen that characteristic peak at $1742 \mathrm{~cm}^{-1}$ is related to stretching vibration of carbonyl $(\mathrm{C}=\mathrm{O})$ for ester group. The peak at $3008.6 \mathrm{~cm}^{-1}$ was assigned to $=\mathrm{C}-\mathrm{H}$ and 
TABLE 1: Fluorescence characteristics of lubricant before and after elimination of fluorescence.

\begin{tabular}{lccc}
\hline Lubricant & The maximum fluorescence intensity $F_{\max }$ & Corresponding EX (nm) & Corresponding EM (nm) \\
\hline E167 & 7.725 & 258 & 332.0 \\
Ordinary lubricant & 115.2 & 300 & 385.6 \\
\hline
\end{tabular}

The fluorescence grades of E167 are 2-3.

TABLE 2: Rheology variation of fresh water mud before and after adding E167.

\begin{tabular}{|c|c|c|c|c|c|}
\hline Experimental condition & Content of E167 (\%) & $\mathrm{AV}(\mathrm{mPa} \cdot \mathrm{s})$ & $\mathrm{PV}(\mathrm{mPa} \cdot \mathrm{s})$ & $\mathrm{YP}(\mathrm{Pa})$ & $\mathrm{FL}_{\mathrm{API}}(\mathrm{mL})$ \\
\hline \multirow{3}{*}{ Room temperature } & 0 & 10.5 & 6 & 4.3 & 19.2 \\
\hline & 0.5 & 11.5 & 6 & 5.7 & 18.4 \\
\hline & 1.0 & 12.5 & 6 & 6.2 & 16.8 \\
\hline \multirow{3}{*}{$150^{\circ} \mathrm{C} \times 16 \mathrm{~h}$} & 0 & 17.0 & 8 & 9.1 & 26.0 \\
\hline & 0.5 & 17.7 & 8 & 9.8 & 24.0 \\
\hline & 1.0 & 18.0 & 8 & 10.1 & 24.0 \\
\hline \multirow{3}{*}{$180^{\circ} \mathrm{C} \times 16 \mathrm{~h}$} & 0 & 18.0 & 7 & 5.1 & 24.0 \\
\hline & 0.5 & 19.0 & 8 & 10.5 & 26.0 \\
\hline & 1.0 & 17.3 & 8 & 7.4 & 24.0 \\
\hline
\end{tabular}

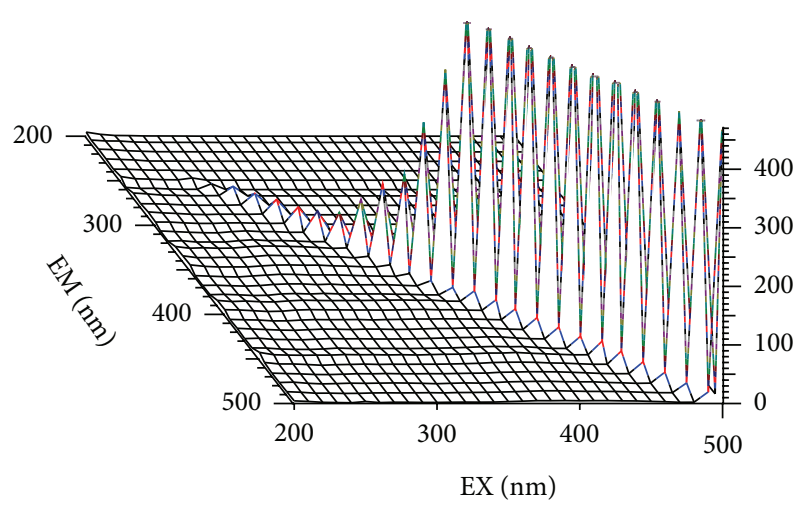

FIGURE 5: FTIR spectra of low fluorescing lubricant with different amount of nitric acid.

the $1552 \mathrm{~cm}^{-1}$ peak was related to stretching vibration of $-\mathrm{C}-\mathrm{NO}_{2}$. The peak at $3008.6 \mathrm{~cm}^{-1}$ was obvious without nitric acid, which decreased with the increase of nitric acid content, and the stretching vibration of $-\mathrm{NO}_{2}$ at $1552 \mathrm{~cm}^{-1}$ occurred simultaneously. When the nitrate concentration is $6 \%$, the peak at $3008.6 \mathrm{~cm}^{-1}$ is not obvious. The variation of peaks in the spectra illustrated that the nitration reaction took place with $\mathrm{C}=\mathrm{C}$ bond broken and $\mathrm{C}-\mathrm{NO}_{2}$ formation.

\subsubsection{Effect of Elimination of Fluorescent Reaction on the Flu-} orescence Characteristics of Lubricant. Table 1 demonstrated the fluorescence characteristics of lubricant before and after elimination of fluorescence, which showed that the maximum fluorescence intensity, the corresponding optimal excitation and emission wavelength are changed.

Figures 6 and 7 are 3D fluorescence spectra of E167 and ordinary lubricant, respectively. Comparing Figures 6 and 7 , the ordinary lubricant shows fluorescence peak curve in three-dimensional map without nitrate. However, the fluorescence intensity peak of E167 was not presented on the

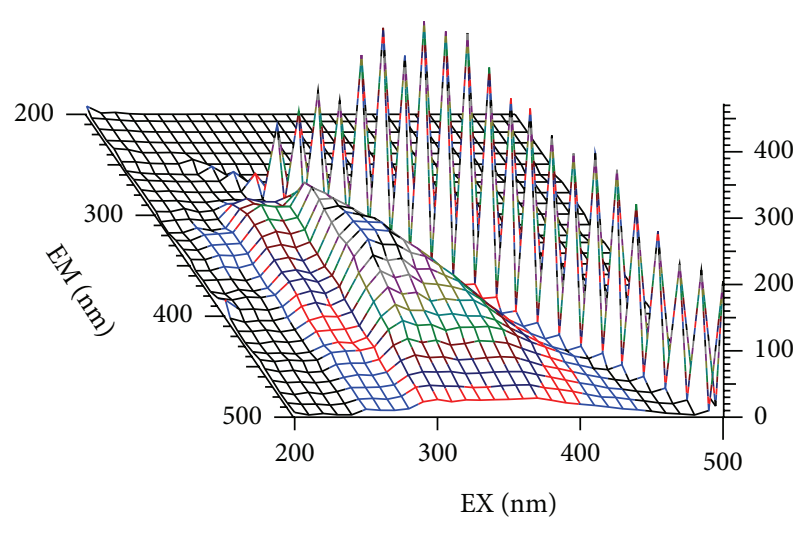

FIGURE 6: 3D fluorescence spectra of E167.

map after eliminating fluorescence. The results illustrated that the low fluorescing lubricant E167 prepared by reacting 4\% liquid nitric acid for 1 hour has low intensity of fluorescence. The strong peaks on the diagonal were produced by the instrument itself, which cannot be avoided when the scan ranges of both EX and MX were set at 200-500 nm.

\subsection{The Comprehensive Performance Evaluation of E167}

3.3.1. Rheological Properties. Adding E167 into fresh water based mud and brine based mud, respectively, the rheological properties of E167 in 5.2\% bentonite fresh water based mud (Weifang, Shandong) and $4 \%$ brine based mud systems were measured and the results were shown in Tables 2 and 3.

It can be seen from Table 2, in fresh water based mud, that both the apparent viscosity and yield point increased slightly, and the filter loss of API decreased mildly after adding into E167.

As shown in Table 3, in brine based mud, the same regularity was obtained: both the apparent viscosity and 


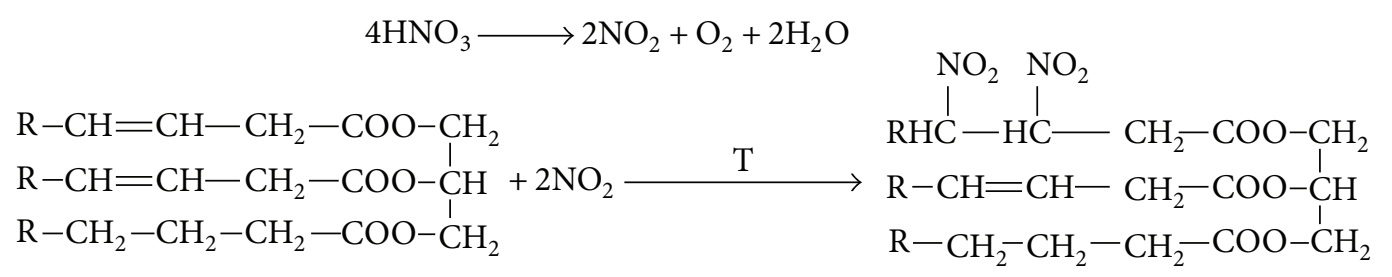

FIGURE 7: 3D fluorescence spectra of ordinary lubricant.

TABLE 3: Rheology variation of brine mud before and after adding E167.

\begin{tabular}{|c|c|c|c|c|c|}
\hline Experimental condition & Content of E167 (\%) & $\mathrm{AV}(\mathrm{mPa} \cdot \mathrm{s})$ & $\mathrm{PV}(\mathrm{mPa} \cdot \mathrm{s})$ & $\mathrm{YP}(\mathrm{Pa})$ & $\mathrm{FL}_{\mathrm{API}}(\mathrm{mL})$ \\
\hline \multirow{3}{*}{ Room temperature } & 0 & 4.5 & 2 & 2.4 & 66 \\
\hline & 0.5 & 4.8 & 3 & 2.2 & 66 \\
\hline & 1.0 & 5.0 & 3 & 2.4 & 68 \\
\hline \multirow{3}{*}{$150^{\circ} \mathrm{C} \times 16 \mathrm{~h}$} & 0 & 3.5 & 3 & 1.0 & 104 \\
\hline & 0.5 & 3.7 & 3 & 1.2 & 96 \\
\hline & 1.0 & 4.0 & 3 & 1.4 & 86 \\
\hline \multirow{3}{*}{$180^{\circ} \mathrm{C} \times 16 \mathrm{~h}$} & 0 & 3.7 & 2 & 1.0 & 112 \\
\hline & 0.5 & 4.0 & 2 & 2.4 & 106 \\
\hline & 1.0 & 4.3 & 3 & 1.2 & 94 \\
\hline
\end{tabular}

TABLE 4: Foaming rate of E167 at different conditions.

\begin{tabular}{lcc}
\hline Sample & Experimental condition & Foaming rate $(\%)$ \\
\hline Distilled water $+0.5 \%$ X-E167 & Room temperature & 3.3 \\
Fresh water mud $+1.0 \%$ X-E167 & Room temperature & 6.7 \\
Fresh water mud $+1.0 \%$ X-E167 & Thermal ageing $120^{\circ} \mathrm{C} \times 16 \mathrm{~h}$ & 5.0 \\
Fresh water mud $+1.0 \%$ X-E167 & Thermal ageing $150^{\circ} \mathrm{C} \times 16 \mathrm{~h}$ & 43.3 \\
\hline
\end{tabular}

Fresh water mud is mixed with $3.7 \%$ bentonite and distilled water (Chifeng Tianyu), $\mathrm{pH}=9, \mathrm{AV}=8-9 \mathrm{mPa} \cdot \mathrm{s}$.

yield point increased slightly, and the filter loss of API decreased, meaning that the addition of E167 had no impact on rheological properties of the drilling fluid.

3.3.2. Foamability. The foaming performance at room temperature and thermal ageing at high temperature were evaluated after adding the E167 into fresh water based mud system. The methods of determining thermal ageing foaming rate are as follows: add $2.00 \mathrm{~g}$ sample into $400 \mathrm{~mL}$ fresh water based mud and put it into the aging tank after stirring $5 \mathrm{~min}$. The mixture was thermal aged for $16 \mathrm{~h}$ at setting temperature, mixing with glass rod and then taking $300 \mathrm{~mL}$ mixture which was stirred for $5 \mathrm{~min}$ at $10000 \mathrm{r} / \mathrm{min}$ speed. After tiring, put the $300 \mathrm{~mL}$ mixture into $500 \mathrm{~mL}$ cylinder in $10 \mathrm{~s}$, read the total volume at $30 \mathrm{~s}$, and then calculate the foaming rate according to the formula.

Table 4 showed that, at the dosage of 1\%, the E167 had weak foamability after thermal ageing for $16 \mathrm{~h}$ at $120^{\circ} \mathrm{C}$, while the foaming was strong with the same time of hot rolling at $150^{\circ} \mathrm{C}$. That is because the fat was hydrolyzed to form fatty acid at high temperature and then reacted with bases to form anionic surfactant sodium carboxylate, causing the enhancement of foaming capacity.
3.3.3. Lubricity. Adding E167 into 5.2\% bentonite fresh water based mud (Weifang, Shandong) and $4 \%$ brine based mud successively, the lubricity and salt resistance were investigated as shown in Table 5.

It can be seen from the table that the E167 has good lubricant performance. In case of changing conditions, such as thermal aged at $180^{\circ} \mathrm{C}$ for $16 \mathrm{~h}$ and even in the $4 \%$ brine based mud, the values of $\Delta K_{f}$ and $\Delta f$ changed a little, which means that the E167 with good lubricity has relatively good temperature resistance and salt resistance.

\subsubsection{Comparison of Properties with Other Low Fluorescence} Lubricants. We selected two kinds of oil based low fluorescence lubricant with comprehensive performance on scene as a contrast sample, which were from Shengli Oilfield (S-WD) and Tarim Oilfield (T-YS), respectively. The properties of lubrication, fluorescence, and foaming rate were determined as shown in Table 6.

Compared with commercially available excellent products, the low fluorescence lubricant E167 prepared in this work has outstanding properties. Moreover, the comprehensive foaming performance after thermal ageing was superior to the contrast sample. 
TABLE 5: The evaluation of lubricity for E167.

\begin{tabular}{lcccc}
\hline Type of mud & Content of E167 (\%) & $\Delta K_{f}(\%)$ & $\Delta f(\%)$ & Testing condition \\
\hline \multirow{3}{*}{ Fresh water mud } & 0.5 & 77.55 & 79.14 & At room temperature \\
& 1.0 & 77.55 & 76.82 & At room temperature \\
& 1.0 & 71.33 & 70.27 & Thermal ageing $180^{\circ} \mathrm{C} \times 16 \mathrm{~h}$ and then at room temperature \\
Brine mud & 0.5 & 75.00 & 62.43 & At room temperature \\
& 1.0 & 77.08 & 66.60 & At room temperature \\
& 1.0 & 73.55 & 64.30 & Thermal ageing $180^{\circ} \mathrm{C} \times 16 \mathrm{~h}$ and then at room temperature \\
\hline
\end{tabular}

TABLE 6: Comparison of three kinds of oil based properties of low fluorescence lubricant.

\begin{tabular}{|c|c|c|c|c|}
\hline \multirow{2}{*}{ Properties } & \multirow{2}{*}{ Methods and technical indicators } & \multicolumn{3}{|c|}{ Low fluorescence lubricant } \\
\hline & & E167 & S-WD & T-YS \\
\hline \multirow{2}{*}{ Lubricity } & $\Delta K_{f}(\%)$ & 77.55 & 75.51 & 77.55 \\
\hline & $\Delta f(\%)$ & 76.82 & 77.02 & 68.07 \\
\hline \multirow{3}{*}{ Fluorescence performance } & $F_{\max }$ & 7.08 & 10.50 & 10.98 \\
\hline & Corresponding of $F_{\max } \mathrm{EX}(\mathrm{nm})$ & 258 & 274 & 376 \\
\hline & Corresponding of $F_{\max } \mathrm{EM}(\mathrm{nm})$ & 332 & 325 & 444 \\
\hline \multirow{3}{*}{ Foaming rate $(\%)$} & Mud $+1 \% \mathrm{X}-\mathrm{E} 167$, at room temperature & 5.0 & 8.3 & 10.0 \\
\hline & Mud $+1 \% \mathrm{X}$-E167, after thermal ageing $120^{\circ} \mathrm{C} \times 16 \mathrm{~h}$ & 6.7 & 13.0 & 31.7 \\
\hline & Mud $+1 \% \mathrm{X}$-E167, after thermal ageing $150^{\circ} \mathrm{C} \times 16 \mathrm{~h}$ & 43.3 & 48.0 & 45.0 \\
\hline
\end{tabular}

\section{Conclusion}

In summary, the low fluorescence lubricant used for drilling fluid was prepared, taking animal and vegetable oil as raw material. The properties were studied by many methods. It is revealed from the experimental results that, with the addition of concentrated nitric acid, the modified lubricant was qualified in low fluorescence and comprehensive good lubricating performance. In view of the influence of temperature, the E167 exhibited good lubricity after thermal ageing at $180^{\circ} \mathrm{C}$ for 16 hours showing properties of high-temperature resistance. The foaming rate of E167 was lower when compared with similar products although which exhibited serious foaming phenomenon.

\section{Conflict of Interests}

The authors declare that there is no conflict of interests regarding the publication of this paper.

\section{References}

[1] D.-J. Li, "Status and advances of drilling fluid lubricants," Petroleum Drilling Techniques, vol. 26, no. 2, pp. 35-38, 1998.

[2] R. Caenn, H. C. H. Darley, and G. R. Gray, Composition and Properties of Drilling and Completion Fluids, Gulf Professional Publishing, 6th edition, 2011.

[3] G.-J. Lv, "Low-fluorescence anti-blocking lubricant for drilling fluid and production method thereof," CN, 101717621 A, 2010-62.

[4] G.-S. Feng, C.-S. Li, H. Tang, and W.-J. Wang, "Compound type vegetable oil lubricating agent for drilling fluid and preparation method thereof," CN, 101760186 A, 2010-6-30.
[5] A. D. Patel, E. Stamatakis, S. Young et al., "High performance water based drilling fluid," US: 2008/0009422 A1, 2008-1-10.

[6] D. Knox and P. Jiang, "Drilling further with water-based fluids-selecting the right lubricant," in Proceedings of the SPE International Symposium on Oilfield Chemistry, pp. 9-15, The Woodlands, Tex, USA, February 2005.

[7] H. Wagner, R. Luther, and T. Mang, "Lubricant base fluids based on renewable raw materials: their catalytic manufacture and modification," Applied Catalysis A, vol. 221, no. 1-2, pp. 429-442, 2001.

[8] N. J. Fox and G. W. Stachowiak, "Vegetable oil-based lubricantsA review of oxidation," Tribology International, vol. 40, no. 7, pp. 1035-1046, 2007.

[9] P. Mousavi, D. Wang, C. S. Grant, W. Oxenham, and P. J. Hauser, "Measuring thermal degradation of a polyol ester lubricant in liquid phase," Industrial and Engineering Chemistry Research, vol. 44, no. 15, pp. 5455-5465, 2005.

[10] S. Z. Erhan, B. K. Sharma, Z. Liu, and A. Adhvaryu, "Lubricant base stock potential of chemically modified vegetable oils," Journal of Agricultural and Food Chemistry, vol. 56, no. 19, pp. 8919-8925, 2008.

[11] B.-R. Höhn, K. Michaelis, and R. Döbereiner, "Load carrying capacity properties of fast biodegradable gear lubricants $\odot$," Lubrication Engineering, vol. 55, no. 11, pp. 15-38, 1999.

[12] B. Krzan and J. Vizintin, "Tribolngical properties of an environmentally adopted universal tractor transmission oil based on vegetable oil," Tribology International, no. 36, pp. 826-832, 2003.

[13] J.-H. Liu and A.-Y. Qiu, "New progress in hydrogenation technology of vegetable oil(I)," China Oils and Fats, vol. 28, no. 8, pp. 13-17, 2003.

[14] S.-Y. Song, "Drilling fluid lubricating additive and its preparing method," CN, 1743404A, 2006-3-8.

[15] H. Chun, W.-L. Xie, and W. Guo, "Study on synthesis and characterization of triethanolamine dilaurate," Cereals \& Oils, no. 7, pp. 11-13, 2008. 
[16] X. Wu, X. Zhang, S. Yang, H. Chen, and D. Wang, "Study of epoxidized rapeseed oil used as a potential biodegradable lubricant," Journal of the American Oil Chemists' Society, vol. 77, no. 5, pp. 561-563, 2000.

[17] A.-J. Liu, "Understanding and pondering over fluorescence problem of drilling fluid additives," Drilling Fluid and Completion Fluid, vol. 20, no. 2, pp. 9-12, 2003.

[18] A. D. Patel, "Non-fluorescing oil-based drilling fluid," US, 5869433, 1999-2-9.

[19] Q/SY, 1088-2007, "Specifications of liquid lubricants used in drilling fluids," China National Petroleum Corporation. 12, 2006.

[20] GB-T, 16783. 1-2006, "Petroleum and natural gas industriesField testing of drilling fluids-Part 1: water-based fluids," China National Standard. 12, 2006.

[21] Q/SY TZ, 0022-2000, "Specifications and analytical methods for drilling fluid lubricants," Tarim Oilfield of China National Petroleum Corporation. 12, 2000.

[22] D. Hace, V. Kovacevic, and D. Pajc-Liplin, "Thermally stimulated oxidative degradation of high impact polystyrene with nitric acid," Polymer Engineering and Science, vol. 36, no. 8, pp. 1140-1151, 1996.

[23] Y.-Q. Liu, Modern Instrumental Analysis, Higher Education Press, Beijing, China, 2006. 

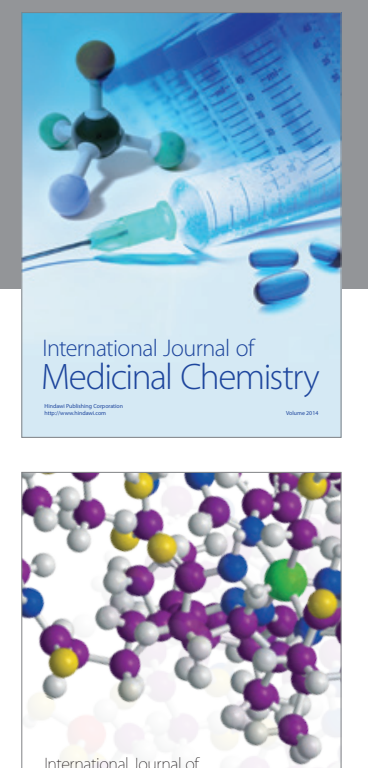

\section{Carbohydrate} Chemistry

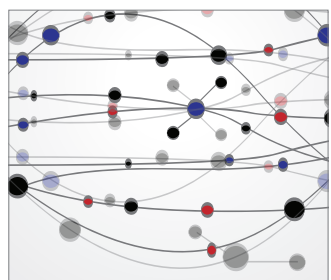

The Scientific World Journal
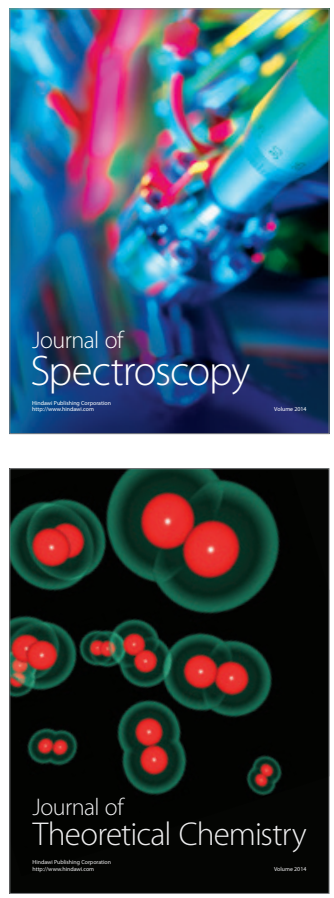
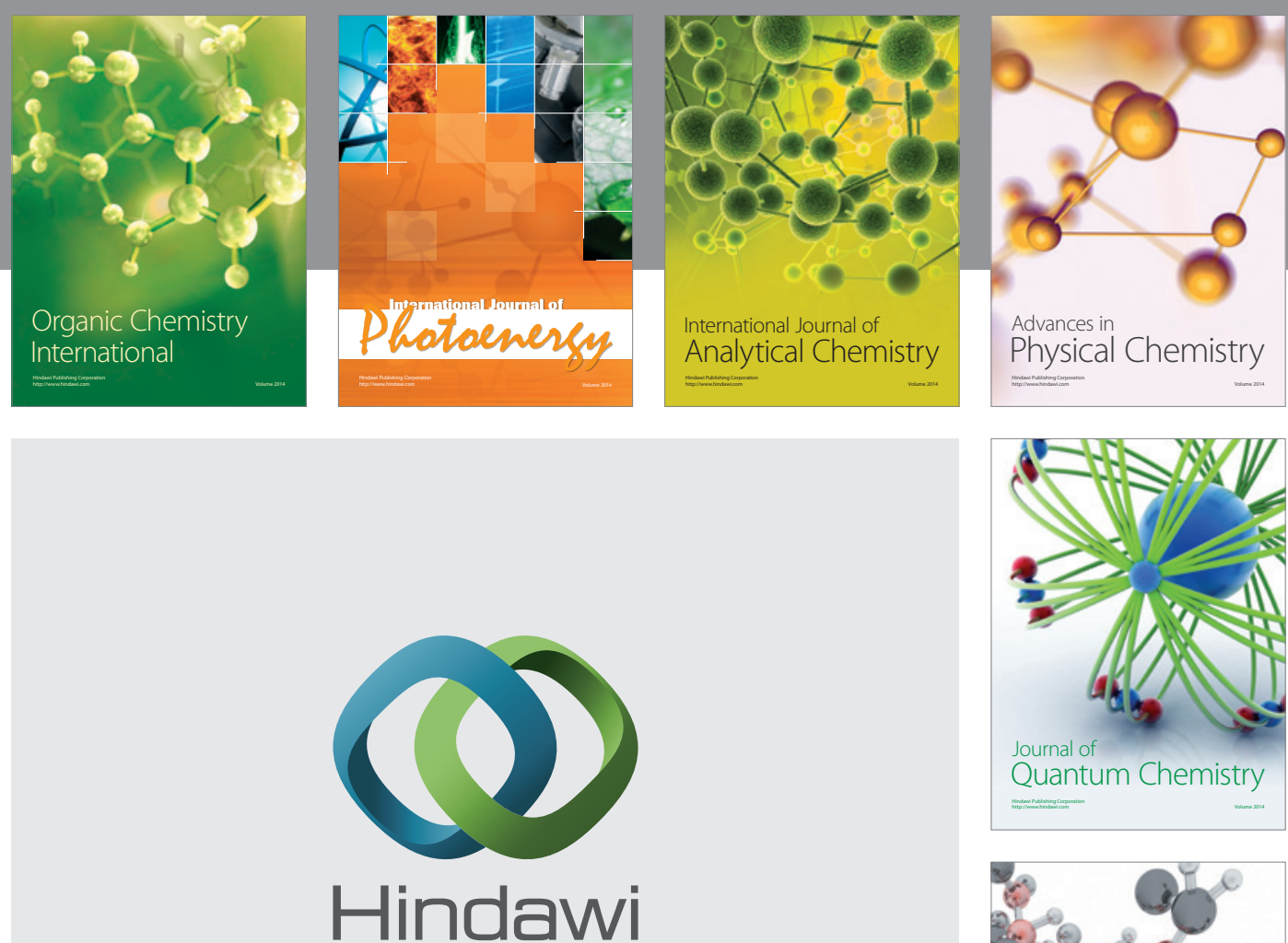

Submit your manuscripts at

http://www.hindawi.com

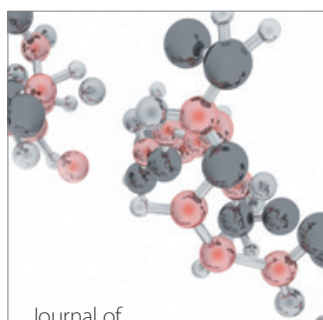

Analytical Methods

in Chemistry

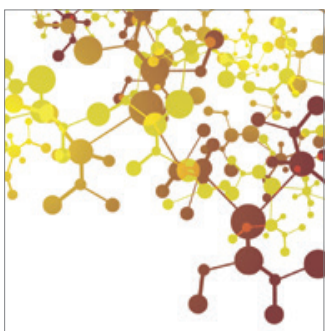

Journal of

Applied Chemistry

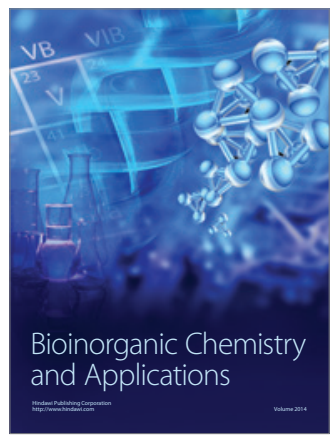

Inorganic Chemistry
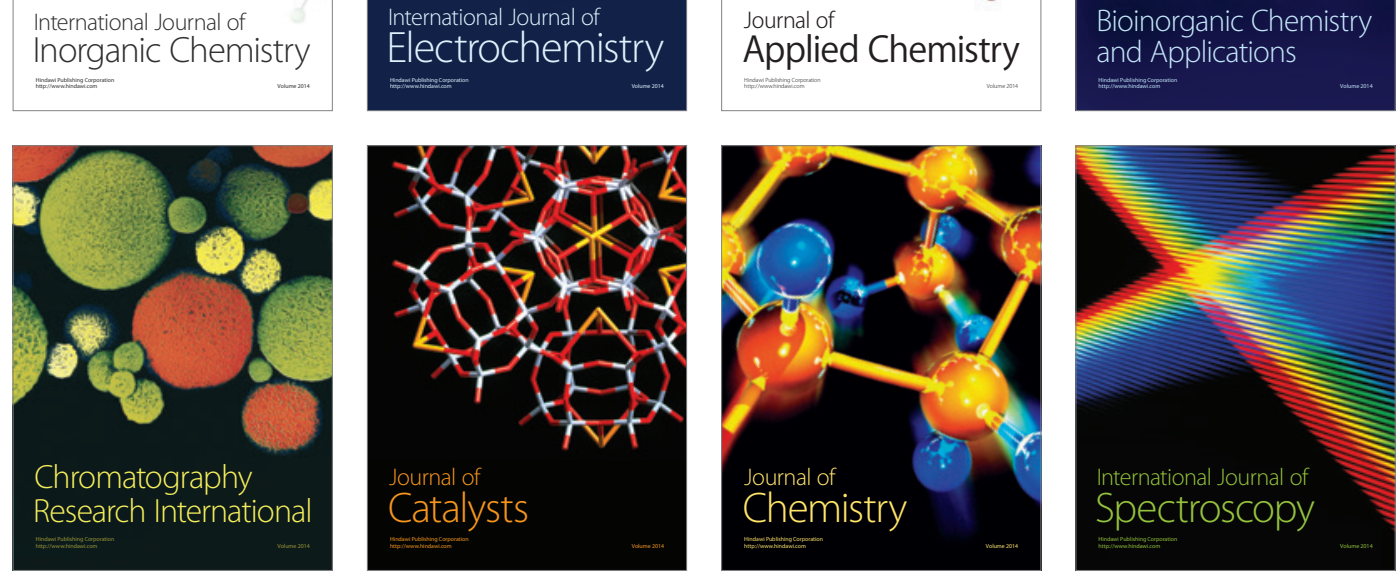